\title{
Fluorescent ZnCdSe/ZnS QDs probes for sensitive copper (II) detection
}

\author{
Zhijie Qin, Qiulin Yue*, Xinli Liu* \\ Shandong Provincial Key Lab. of Microbial Engineering, Qi Lu University of Technology (Shandong \\ Academy of Sciences), Jinan 250353, P.R. China \\ *Corresponding author: Qiulin Yue \& Xinli Liu \\ Tel \& fax: +86 53189631776 ; \\ E-mail address: yueqiulin88@163.com (Q.L.Y.) or vip.IxI@163.com (X.L.L.)
}

\begin{abstract}
Keywords: copper (II); metal ions; fluorescence sensor; ZnCdSe/ZnS QDs; fluorescence quenching; detection
\end{abstract}

Abstract Considering the fact that copper (II) $\left(\mathrm{Cu}^{2+}\right)$ act as a dietary need but toxic metal ions, its detection and quantification is very much important for human healthy diet and environmental risk assessment. Herein, we introduced a sensitive fluorescence sensor for the detection of $\mathrm{Cu}^{2+}$ based on $\mathrm{ZnCdSe} / \mathrm{ZnS} \mathrm{QDs}$, whose fluorescence quenching was well linear with $\mathrm{Cu}^{2+}$ concentration. And a detection limit as low as $5 \mathrm{nM}$ was obtained. Moreover, the recovery experiment was performed and the satisfactory recovery rate was obtained. The results indicated that the proposed ZnCdSe/ZnS QDs probes possessed a good performance for the detection of $\mathrm{Cu}^{2+}$. Therefore, a effective fluorescence sensor was developed for the detection of $\mathrm{Cu}^{2+}$ at a sensitive level.

\section{Introduction}

Contamination caused by heavy metal ions has been attracted much attention worldwide on account of the fact that heavy metal ions such as $\mathrm{Cu}^{2+}, \mathrm{Hg}^{2+}, \mathrm{Pb}^{2+}, \mathrm{Ni}^{2+}, \mathrm{Co}^{2+}$, etc. were related to an immense danger to food safety and several diseases associated with environmental pollution [1-3]. Among various heavy metal ions, copper, when appropriate amount exists, plays a vital function in the metabolism process of human beings such as cellular respiration, bone and connective tissue formation, serves as a co-factor for various metalloenzymes [4]. Nevertheless, as one of the heavy metals, excessive accumulation of copper in body tissues may not only cause brain and liver damage, but also result in some neurodegenerative diseases, for instance, Alzheimer's disease [5]. Therefore, as a dietary need but toxic metal ions, it requires a trace detection with efficient, simple and inexpensive methods in order to have a close monitor to the daily intake content of copper and to assess the environmental risk.

During recent years, a variety of instrumental techniques including electrochemical analysis (EC) [6], atomic absorption spectrometry (AAS) [7], inductively coupled plasma mass spectrometry (ICP-MS) [8] have been applied for the copper detection. However, these conventional methods are not suitable for routine detection due to the disadvantages of costly instruments, time-consuming process and complicated sample preparation. Compared with traditional methods, fluorescence sensors for $\mathrm{Cu}^{2+}$ based on quantum dots (QDs) have attracted much of interest on account of high sensitivity, low limit of detection (LOD) and relatively convenient operation. QDs are important fluorescent semiconductor nano-crystals with typically sizes in the range of 1 to $12 \mathrm{~nm}$ [9]. These nanoparticles possess distinguished tunable electrical and optical properties due to quantum confinement effects, such as highly photo-stable, broad absorption, narrow and size-dependent emission spectra, long fluorescence lifetime and high quantum yield (QY) [10]. Due to these unique traits, QDs have gained considerable interest in fields of fluorescence sensors. In previous reports, many fluorescent QDs were applied to be the sensor for $\mathrm{Cu}^{2+}$ detection. For example, with the combination of the dual selective effects of both yeast membrane and capping proteins of QDs, Su et al. offered a rapid and reliable way of $\mathrm{Cu}^{2+}$ detection in water and plasma with a detection limit of 1 $\mu \mathrm{mol} / \mathrm{L}$ and $2 \mu \mathrm{mol} / \mathrm{L}$, respectively [5]. Yan et al. reported that CdSe QD-containing Bacillus 
licheniformis cells were used as whole fluorescent bio-probes to detect $\mathrm{Cu}^{2+}$ in water, which demonstrated a low limit of detection $(0.91 \mathrm{mM})$ [11].

Herein, we introduced a sensitive fluorescence sensor for the detection of $\mathrm{Cu}^{2+}$ based on $\mathrm{ZnCdSe} / \mathrm{ZnS}$ QDs with a detection limit as low as $5 \mathrm{nM}$. Firstly, different kinds of other common metal ions were added to the $\mathrm{ZnCdSe} / \mathrm{ZnS}$ QDs probes solutions under the same conditions, in order to investigate the selectivity of the $\mathrm{ZnCdSe} / \mathrm{ZnS}$ QDs probes for $\mathrm{Cu}^{2+}$ determination. With L-cysteine added to the test solution to eliminate mercury ion interference, $\mathrm{ZnCdSe} / \mathrm{ZnS}$ QDs probes showed good selectivity for $\mathrm{Cu}^{2+}$. Then, the fluorescence quenching of $\mathrm{ZnCdSe} / \mathrm{ZnS}$ QDs probes by $\mathrm{Cu}^{2+}$ was quantitatively measured to plot calibration curves as a mathematic model. Finally, the recovery experiment was carried out with the proposed fluorescence sensor and the satisfactory recovery rate was obtained. The results illustrated that the proposed fluorescence sensor possessed a good performance for the detection of $\mathrm{Cu}^{2+}$

\section{Experimental}

Chemicals and instrument. L-cysteine, phosphates and all kinds of heavy metal ions were purchased from the Sinopharm Chemical Reagent Co., Ltd. ZnCdSe/ZnS QDs solution (8 $\mu$ M, diluted 200 fold with phosphate buffered saline before used) was obtained from the Wuhan Jiayuan Quantum Dots Co., Ltd, China. All chemicals were of analytical reagent grade and were used as received without any further purification. Milli-Q water with a resistivity higher than $18 \mathrm{M} \Omega \mathrm{cm}^{-1}$ was employed to prepare all of the solutions. Phosphate buffered saline (PBS, pH 7.4, $10 \mathrm{mM} \mathrm{KH}_{2} \mathrm{PO}_{4}$ and $10 \mathrm{mM} \mathrm{K}_{2} \mathrm{HPO}_{4}$ ) was used as an solvent for all the fluorescence measurements. PL spectra were obtained with a HITACHI F-4600 luminescence spectrometer (Japan) with an excitation wavelength of $320 \mathrm{~nm}$.

Detection of metal ions. Firstly, in order to investigate the selectivity of the $\mathrm{ZnCdSe} / \mathrm{ZnS}$ QDs probes for $\mathrm{Cu}^{2+}$ determination, $10 \mu \mathrm{L}$ different kinds of metal ions ( the final concentrations of different ions were $100 \mathrm{nM}$ of $\mathrm{Mn}^{2+}, \mathrm{Mg}^{2+}, \mathrm{Cu}^{2+}, \mathrm{Co}^{2+}, \mathrm{Ca}^{2+}, \mathrm{K}^{+}, \mathrm{Pb}^{2+}, \mathrm{Ba}^{2+} \mathrm{Li}^{2+}, \mathrm{Cd}^{2+}, \mathrm{Hg}^{2+}, \mathrm{Zn}^{2+}, \mathrm{Fe}^{2+}, \mathrm{Na}^{+}, \mathrm{Ni}^{+}$ and $\mathrm{Al}^{3+}$ ) were added to $10 \mu \mathrm{L} \mathrm{ZnCdSe/ZnS} \mathrm{QDs} \mathrm{probes} \mathrm{solutions} \mathrm{and} \mathrm{the} \mathrm{final} \mathrm{solution} \mathrm{was} \mathrm{diluted} \mathrm{to}$ $1.0 \mathrm{~mL}$ with a $10 \mathrm{mM}$ Phosphate buffered saline of $\mathrm{pH}$ 7.4. The mixtures were then shaken vigorously for seconds before measuring the fluorescence spectra. Then, with $10 \mu \mathrm{L}$ L-cysteine $(100 \mathrm{mM})$ introduced to the test solution to eliminate mercury ion interference, $\mathrm{ZnCdSe} / \mathrm{ZnS}$ QDs probes showed good selectivity for $\mathrm{Cu}^{2+}$. Thirdly, the fluorescence quenching of $\mathrm{ZnCdSe} / \mathrm{ZnS}$ QDs probes by $\mathrm{Cu}^{2+}$ was quantitatively measured to plot calibration curves as a mathematic model. A calibration curve for measuring $\mathrm{Cu}^{2+}$ ion in PBS was achieved as followed: $10 \mu \mathrm{L} \mathrm{Cu}^{2+}$ solutions with different final concentrations $(0,4,5,8,20,30,50,70,90$ and $100 \mathrm{nM})$ respectively were added to $10 \mu \mathrm{L}$ $\mathrm{ZnCdSe} / \mathrm{ZnS}$ QDs probes solutions and diluted to $1.0 \mathrm{~mL}$ with a $10 \mathrm{mM}$ PBS of $\mathrm{pH}$ 7.4. The mixtures were then mixed vigorously for seconds before measuring their corresponding fluorescence spectra. Finally, to assess its recovery rate, $\mathrm{Cu}^{2+}$ solutions with three final concentrations $(7,60$ and $80 \mathrm{nM})$ respectively were prepared as the above procedure and the corresponding fluorescence spectra of mixtures were measured in the same way.

\section{Results and Discussion}

Selectivity of the proposed fluorescence biosensor. To evaluate the selectivity of $\mathrm{ZnCdSe} / \mathrm{ZnS}$ QDs probes' detection for $\mathrm{Cu}^{2+}, 16$ kinds of metal ions, $\mathrm{Mn}^{2+}, \mathrm{Mg}^{2+}, \mathrm{Cu}^{2+}, \mathrm{Co}^{2+}, \mathrm{Ca}^{2+}, \mathrm{K}^{+}, \mathrm{Pb}^{2+}, \mathrm{Ba}^{2+}, \mathrm{Li}^{2+}$, $\mathrm{Cd}^{2+}, \mathrm{Hg}^{2+}, \mathrm{Zn}^{2+}, \mathrm{Fe}^{2+}, \mathrm{Na}^{+}, \mathrm{Ni}^{+}$and $\mathrm{Al}^{3+}$ at the same concentration were investigated respectively. Fig. 1 shows the efficiencies of $\mathrm{ZnCdSe} / \mathrm{ZnS}$ QDs probe with 16 kinds of metal ions. Fluorescence intensity of $\mathrm{ZnCdSe} / \mathrm{ZnS}$ QDs was defined as $100 \%$. With a concentration of $100 \mathrm{nM}$, most of the mentioned ions did not make significant impacts on the fluorescence intensity of $\mathrm{ZnCdSe} / \mathrm{ZnS}$ QDs. However, $\mathrm{ZnCdSe} / \mathrm{ZnS}$ QDs probes were quenched when either $\mathrm{Cu}^{2+}$ or $\mathrm{Hg}^{2+}$ ion was existed. According to the reference [5], the quenching of QDs fluorescence intensity by $\mathrm{Cu}^{2+}$ and $\mathrm{Hg}^{2+}$ was due to the precipitation or agglomeration of formative new substances with lower solubility than the original QDs. For instance, Zhao et al. [3] revealed that CdS/ZnS QDs could be used as a fluorescence probe 
for $\mathrm{Cu}^{2+}$ determination because when $\mathrm{Cu}^{2+}$ was added to the solution, $\mathrm{Cu}^{2+}$ could exchange with $\mathrm{Cd}^{2+}$ and $\mathrm{Zn}^{2+}$ to form $\mathrm{CuS}$ which had much lower solubility. Then, the structure of the CdS/ZnS QDs was changed and the intensity decreased evidently. Therefore, the fluorescence intensity of CdS/ZnS QDs could be selectively quenched by $\mathrm{Cu}^{2+}$. According to Lai et al. [12], CdS QDs could be selectively quenched by $\mathrm{Cu}^{2+}$ because of the same mechanism. On the other hand, Du et al. [13] speculated that $\mathrm{Hg}^{2+}$ could quench the fluorescence of $\mathrm{Cu}_{2} \mathrm{~S}$ QDs mainly via electron transfer with cation exchange and aggregate-induced quenching, which had the similar phenomena with $\mathrm{Cu}^{2+}$ quenching. And $\mathrm{Lu}$ 's research also proved the same mechanism [14].

(a)

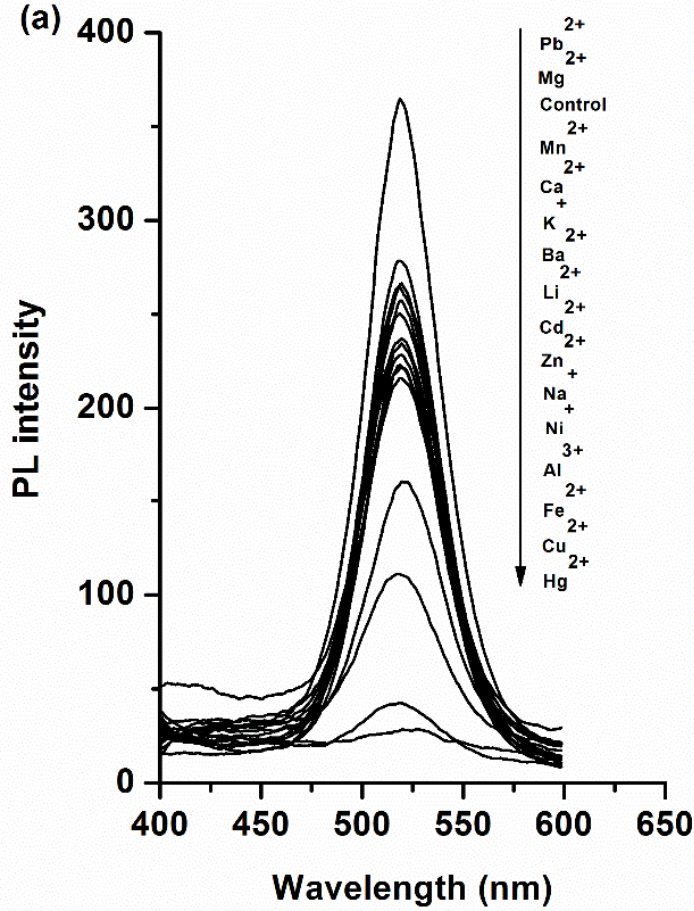

(b)

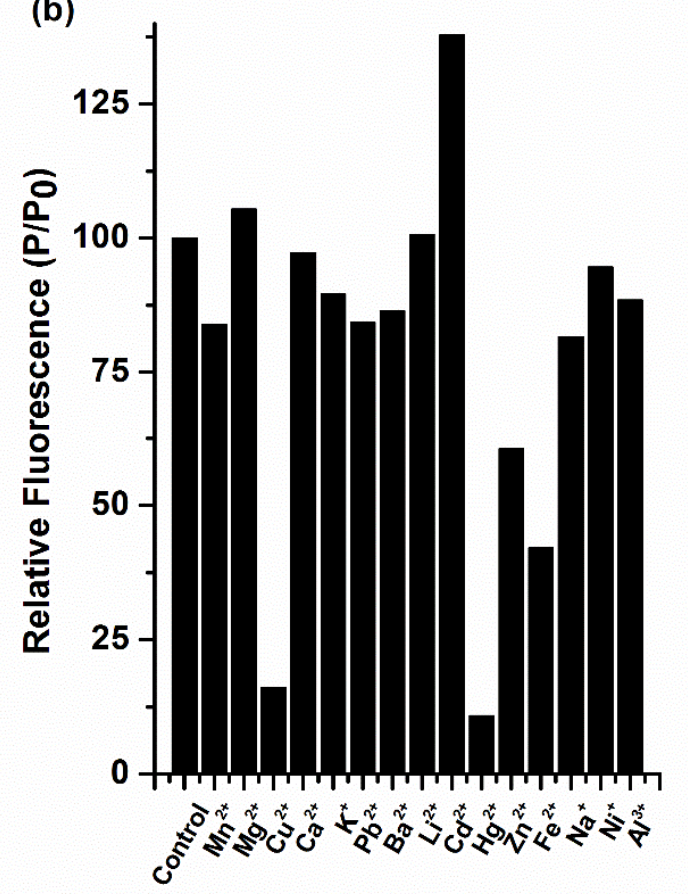

Fig. 1: Selectivity of the proposed sensor toward $\mathrm{Cu}^{2+}$ ions (performed in $10 \mathrm{mM}$ PBS at a $\mathrm{pH}$ of 7.4; the final concentrations of all of the metal ions were $100 \mathrm{nM}$ ). (a) Fluorescence intensity of $\mathrm{ZnCdSe} / \mathrm{ZnS}$ QDs probes in the presence of various metal ions (b) Relative fluorescence $\left(\mathrm{P} / \mathrm{P}_{0}\right)$ were achieved in the absence and presence of each metal ion, respectively.

The results in Fig. 1 suggested that a method to selectively detecting $\mathrm{Cu}^{2+}$ was necessary. As shown in Fig. 2, compared with the fluorescence intensity of the $\mathrm{Cu}^{2+}$ system, that of the $\mathrm{Hg}^{2+}$ system remained stable after $10 \mathrm{~min}$ of L-cysteine treatment. The result indicated that L-cysteine could eliminate $\mathrm{Hg}^{2+}$ interference effectively. The fluorescence recovery of $\mathrm{ZnCdSe} / \mathrm{ZnS}$ QDs- $\mathrm{Hg}^{2+}$-L-cysteine system could be because that $\mathrm{Hg}^{2+}$ probably reacted with L-cysteine through chelation. The phenomena was similar with an previous report [15], in which the added GSH chelated with $\mathrm{Hg}^{2+}$ selectively and lead to the fluorescence recovery of QDs, whose fluorescence was quenched by $\mathrm{Hg}^{2+}$. 


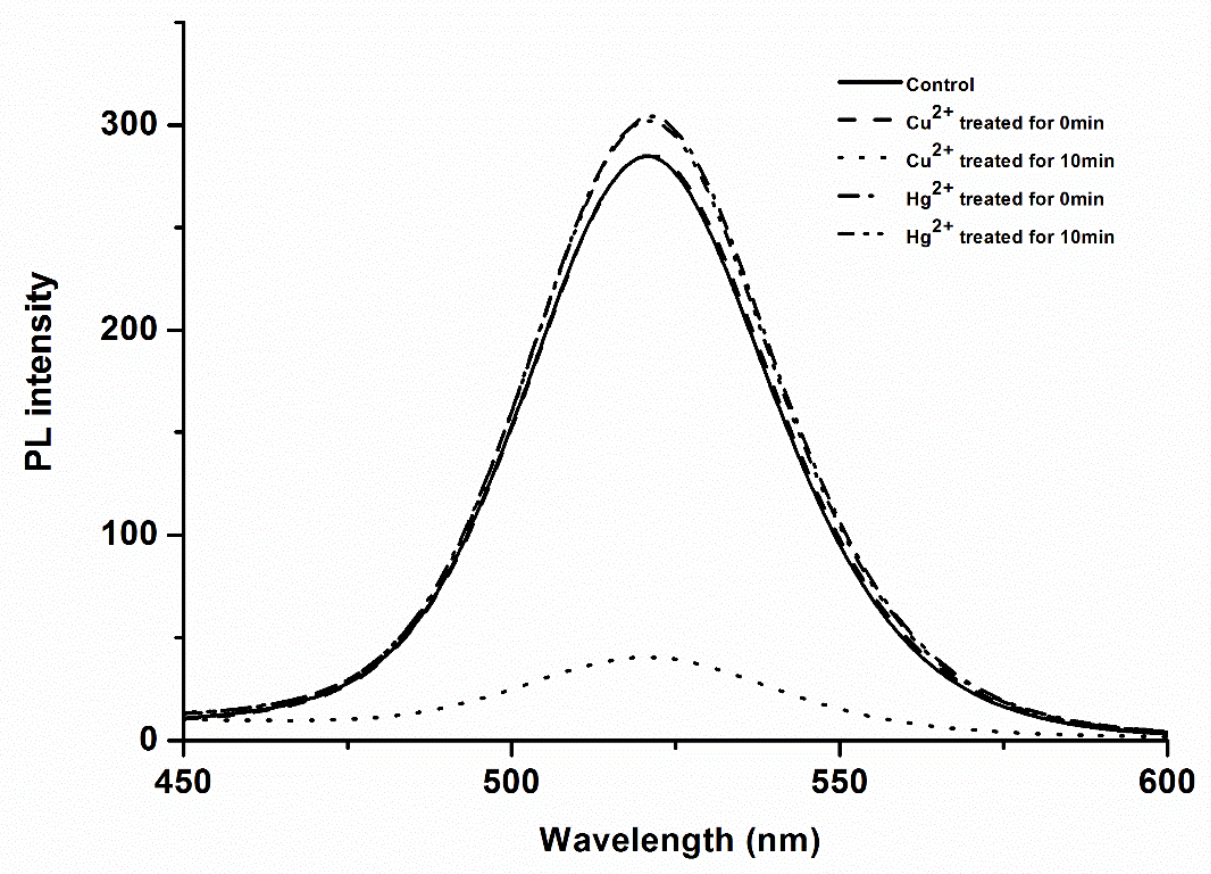

Fig. 2: The fluorescence recovery of $\mathrm{Cu}^{2+}$ and $\mathrm{Hg}^{2+}$ system treated by L-cysteine for 0 min and 10 min, respectively.

Quantitative relationship and recovery experiment. As shown in Fig. 3a, with the increase of $\mathrm{Cu}^{2+}$ concentration from $0 \mathrm{nM}$ to $100 \mathrm{nM}$, the fluorescence intensities of $\mathrm{ZnCdSe} / \mathrm{ZnS}$ QDs probes displayed a gradual decrease in fluorescence at $520 \mathrm{~nm}$ with increasing $\mathrm{Cu}^{2+}$ concentration, demonstrating the feasibility of $\mathrm{Cu}^{2+}$ detection by fluorescence quenching protocol. And the relationship between fluorescence intensity of $\mathrm{ZnCdSe} / \mathrm{ZnS}$ QDs and $\mathrm{Cu}^{2+}$ concentration was nicely described by the Stern-Volmer equation (Fig. 3b). Thus, a Linear correlation graph was established according to the well-known Stern-Volmer equation (Eq. 1):

$$
\mathrm{P}_{0} / \mathrm{P}=1+\mathrm{K}_{\mathrm{SV}}\left[\mathrm{Cu}^{2+}\right]
$$

where $\mathrm{P}_{0}$ and $\mathrm{P}$ refer to the fluorescence intensities of the QDs before and after adding $\mathrm{Cu}^{2+}$, respectively. $\mathrm{K}_{\mathrm{SV}}$ is the Stern-Volmer quenching constant, and $\left[\mathrm{Cu}^{2+}\right]$ is the concentration of $\mathrm{Cu}^{2+}$. Accordingly, a plot of $\mathrm{P}_{0} / \mathrm{P}$ vs. $\left[\mathrm{Cu}^{2+}\right]$ gave a calibration curve in the range of 5 to $100 \mathrm{nM}$ with a regression equation (Eq. 2) of

$$
y=0.017 x+0.9307
$$

(where y represents to $\mathrm{P}_{0} / \mathrm{P}$ and $\mathrm{x}$ represents $\mathrm{Cu}^{2+}$ concentration), and correlation coefficient $\left(\mathrm{R}^{2}\right)$ of 0.9924 . The limit of detection (LOD) was $5 \mathrm{nM}$, which was lower than the previously reported [5, 11]. To apply the proposed QDs probes for $\mathrm{Cu}^{2+}$ detection, three concentrations of $\mathrm{Cu}^{2+}$ were prepared and spiked as summarized in Table 1 . A good recovery of spiked $\mathrm{Cu}^{2+}$ by proposed method was observed. 

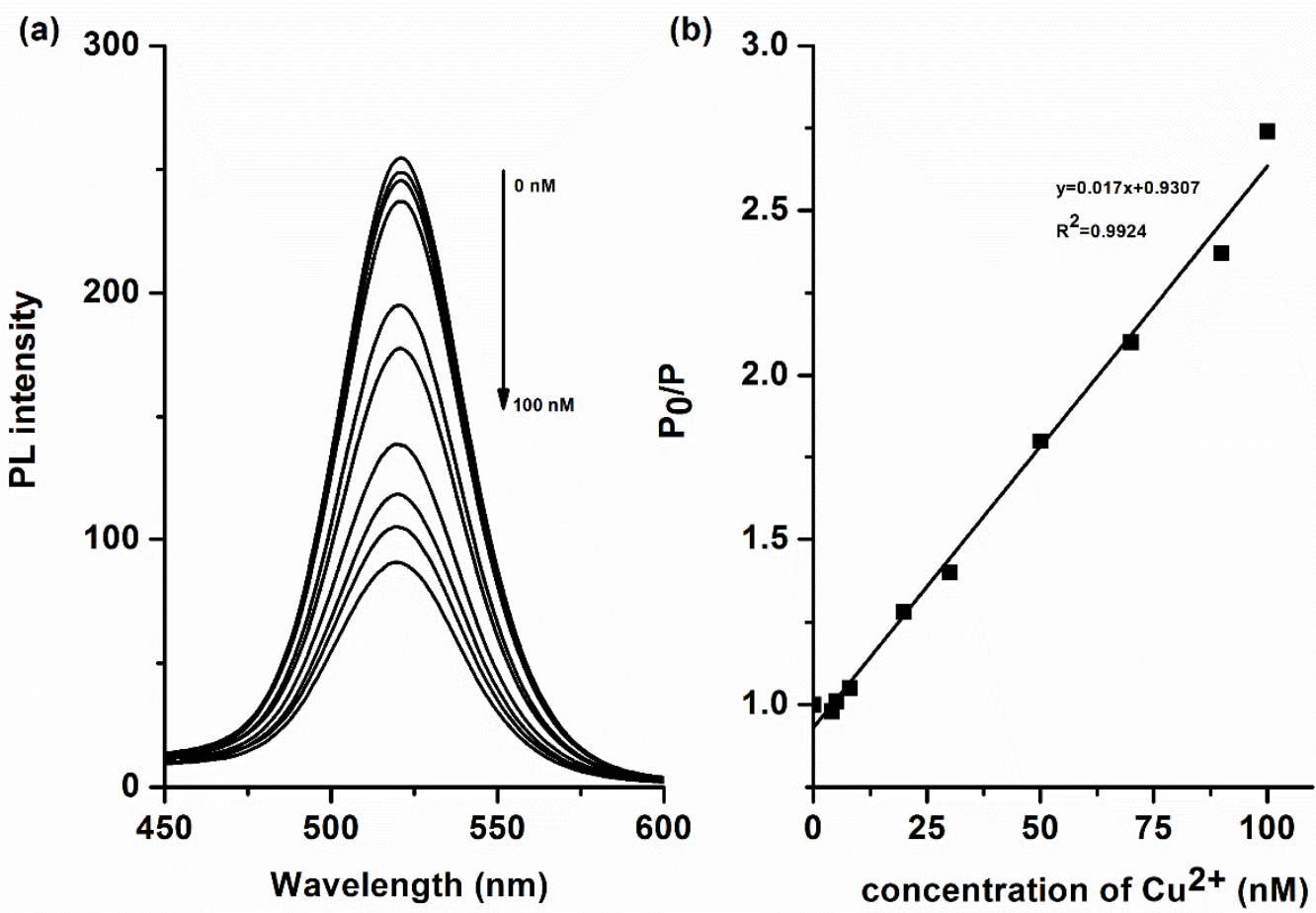

Fig. 3: The relationship between fluorescence intensity of $\mathrm{ZnCdSe} / \mathrm{ZnS}$ QDs and $\mathrm{Cu}^{2+}$ concentration. (a) Fluorescence intensity of $\mathrm{ZnCdSe} / \mathrm{ZnS}$ QDs probes upon the exposure to different concentrations of $\mathrm{Cu}^{2+}$. The concentration of spiked $\mathrm{Cu}^{2+}$ was $0,4,5,8,20,30,50,70,90$ and $100 \mathrm{nM}$ from the top to the bottom, respectively. (b) The calibration curves between fluorescence intensity of $\mathrm{ZnCdSe} / \mathrm{ZnS}$ QDs and $\mathrm{Cu}^{2+}$ concentration.

Table 1: Analytical results for the determination of $\mathrm{Cu}^{2+}$ samples using the proposed sensor

\begin{tabular}{cccc}
\hline Quantity added [nM] & Quantity found [nM] & recovery rate [\%] & RSD [\%] \\
\hline 7 & 6.602 & 94.32 & 4.02 \\
60 & 66.26 & 110.43 & 7.38 \\
80 & 78.73 & 98.42 & 1.12 \\
\hline
\end{tabular}

\section{Conclusions}

To conclude, with L-cysteine introduced to the test solution to eliminate mercury ion interference, we successfully made use of sensitive $\mathrm{ZnCdSe} / \mathrm{ZnS}$ QDs probes for detection of $\mathrm{Cu}^{2+}$. Fluorescence quenching of $\mathrm{ZnCdSe} / \mathrm{ZnS}$ QDs presumably by above referenced mechanism was linear with $\mathrm{Cu}^{2+}$ concentration. And a detection limit as low as $5 \mathrm{nM}$ was obtained. Moreover, the recovery experiment was performed with the proposed method and the satisfactory recovery rate was obtained. The results indicated that the proposed $\mathrm{ZnCdSe} / \mathrm{ZnS}$ QDs probes possessed a good performance for the detection of $\mathrm{Cu}^{2+}$.

\section{Acknowledgements}

This work was financially supported by Natural Science Foundation of Shandong Province (ZR2016CQ28) and Science and Technology Major Project of Shandong Province (2015ZDXX0403B01) 


\section{References}

[1] J. Zhu, Z. J. Zhao, J. J. Li and J. W. Zhao: Spectrochim. Acta A Mol. Biomol. Spectrosc Vol. 177 (2017), p.140

[2] J. L. Chen, Y. X. Zhu and Y. Zhang, Spectrochim. Acta A Mol. Biomol. Spectrosc Vol. 164 (2016), p. 98

[3] G. H. Zhao, X. J. Li, Y. B. Zhao, Y. Y. Li, W. Cao and Q. Wei, Anal Vol. 142 (2017), p. 3272

[4] H. M. Li, X. F. Wang, Z. Cai, L. Lu, J. Tao, B. Sun, Y. Y. Yang, Q. Xu, Z. Q. Yu and P. Zhao, Anal. Bioanal. Chem Vol. 409 (2017), p. 6655

[5] Y. L. Su, Q. Q. Du, X. C. Qu, D. Y. Wan, Y. H. Liu, C. Wang, Z. Y. Yan and S. M. Wu, RSC Adv Vol. 6 (2016), p. 28187

[6] L. D. Ji, Q. Cheng, K. B. Wu and X. F. Yang, Sensor. Actuat. B-CHEM Vol. 231 (2016), p. 12

[7] P. H. Liao, S. J. Jiang and A. C. Sahayam, J. Anal. At. Spectrom Vol. 27 (2012), p. 1518

[8] J. F. Ayala-Cabrera, M. J. Trujillo-Rodriguez, V. Pino, O. M. Hernandez-Torres, A. M. Afonso and J. Sirieix-Plenet, Int. J. Environ. Anal. Chem Vol. 96 (2016), p. 101

[9] Samadi-Maybodi A, Sadeghi-Maleki M R, Spectrochim. Acta A Mol. Biomol. Spectrosc Vol. 152 (2016), p. 156

[10] M. Borovaya, Y. Pirko, T. Krupodorova, A. Naumenko, Y. Blume and A. Yemets, Biotechnol. Biotec. Eq Vol. 29 (2015), p. 1156

[11] Z. Y. Yan, Q. Q. Du, D. Y. Wan, H. Lv, Z. R. Cao and S. M. Wu, Enzyme Microb. Technol Vol. 107 (2017), p. 41

[12] S. J. Lai, X. J. Chang and C. Fu, Mikrochim. Acta Vol. 165 (2009), p. 39

[13] W. L. Du, L. Liao, L. Yang, A. M. Qin, and A. H. Liang, Sci. Rep Vol. 7 (2017), p. 11451

[14] L. Q. Lu, T. Tan, X. K. Tian, Y. Li and P. Deng, Anal. Chim. Acta Vol. 986 (2017), p. 109

[15] X. Tan, J. Yang, Q. Li, and Q. Yang, Anal Vol. 140 (2015), p. 6748 